\title{
Diagnosis of Acute Pancreatitis
}

\author{
AlmaLlukacaj ${ }^{1}$, Majlinda Naco ${ }^{2}$ \\ ${ }^{1}$ Service nr.1 of Surgery Department, Hospital University Center “Mother Theresa” Rruga e Dibres Nr. 372, Tirana, Albania \\ ${ }^{2}$ Department of Anaesthesiology, Hospital University Center "Mother Theresa” Rruga e Dibres Nr. 372, Tirana, Albania
}

\begin{abstract}
Acute pancreatitis is a common disorder. Its diagnosis, prognosis and management have presented significant challenges to clinicians, surgeons, and radiologists. This article reviews historical and current concepts in the diagnosis of acute pancreatitis and its complications, including radiological diagnosis, as well as the different systems of acute pancreatitis course prediction.
\end{abstract}

Keywords: Acute pancreatitis, serum amylase, BUN, CRP, computed tomography

\section{Introduction}

Acute pancreatitis is a pathology which requires hospital admissions for management of the disease. Acute pancreatitis in its many forms often presents complex diagnostic and management challenges to physicians, surgeons, and radiologists. In this article we discuss current practices in the diagnosis of acute pancreatitis.

\section{Diagnosis and Severity Assessment of Acute Pancreatitis}

Diagnosis of acute pancreatitis is based on patient symptoms, physical examination, laboratory analysis, and radiological data. According to practice guidelines published in 2006, a diagnosis of acute pancreatitis requires two out of three main features: (1) abdominal pain typical for acute pancreatitis, (2) serum amylase and/or lipase greater than or equal to three times the upper normal limit; and (3) evidence of acute pancreatitis on computed tomography (CT) scans[1].

Almost all patients with acute pancreatitis have acute upper abdominal pain at onset, which is usually severe and constant. The pain may be confined to the epigastrium or may be diffuse throughout the abdomen. Patients frequently experience nausea and vomiting as well. However, the differential diagnosis must be done with biliary colic, gastric or duodenal ulcer perforation and bowel obstruction, mesenteric ischemia, aortic aneurysm or dissection, and even inferior myocardial infarction [1].

Physical signs and symptoms often depend on the severity of the attack. Systemic features include fever and tachycardia, and in severe cases patients may be in shock. In mild disease, the epigastrium may be minimally tender on physical examination, whereas patients with severe pancreatitis may have abdominal distention, tenderness, and guarding. Jaundice can occur due to choledocholithiasis or due to compression of the common bile duct from the edema of the pancreas head.

Laboratory analysis for work-up of patients with acute pancreatitis includes serum amylase and lipase levels, as well as a complete blood count, electrolytes, blood urea nitrogen (BUN), creatinine, liver function tests, and inflammatory markers, such as $\mathrm{C}$ reactive protein (CRP). In a retrospective analysis, the sensitivity for lipase and amylase levels in the diagnosis of acute pancreatitis were $96.6 \%$ and $78.6 \%$, and the specificity were $99.4 \%$ and $99.1 \%$, respectively [2]. Lipase has a longer half-life than amylase, which makes it a useful diagnostic measure in patients with delayed presentation in whom amylase levels may have already returned to normal. The level of pancreatic enzyme elevation does not correlate with the severity of the disease, and serial measurements should not be used as a tool to assess the prognosis or progress of acute pancreatitis. CRP levels $>150 \mathrm{mg} / \mathrm{dL}$ at 48 hours is a sign of severe pancreatitis [2].

Initial assessment of severity is one of the most important issues in the management of acute pancreatitis. Approximately $15-20 \%$ of patients with acute pancreatitis will develop severe disease, often resulting from pancreatic necrosis. An international symposium held in Atlanta, Georgia, in 1992, established a clinically based classification system for acute pancreatitis (Table 1) [3].

Table 1: Atlanta Criteria for Severity [2]. (Early Prognostic Signs: Ranson's Score $\geq 3$; APACHE II Score $\geq 8$ )

\begin{tabular}{|c|c|}
\hline Feature & Symptoms \\
\hline \multirow{4}{*}{ Organ failure } & Shock (systolic blood pressure $<90 \mathrm{mmHg})$ \\
\cline { 2 - 2 } & Pulmonary insufficiency $\left(\mathrm{PaO}_{2}<60 \mathrm{mmHg}\right)$ \\
\cline { 2 - 2 } Local & $\begin{array}{c}\text { Renal failure (serum creatinine }>2 \mathrm{mg} / \mathrm{dL} \text { after } \\
\text { rehydration) }\end{array}$ \\
\cline { 2 - 2 } complications & $\begin{array}{c}\text { Pancreatic necrosinal bleeding }(>500 \mathrm{~mL} / 24 \mathrm{~h}) \\
>3 \mathrm{~cm})\end{array}$ \\
\cline { 2 - 2 } & $\begin{array}{c}\text { Pancreatic abscess (circumscribed collection of pus } \\
\text { containing little or no pancreatic necrosis) }\end{array}$ \\
\cline { 2 - 2 } & $\begin{array}{c}\text { Pancreatic pseudocyst (collection of pancreatic juice } \\
\text { enclosed by a wall of fibrous tissue or granulation } \\
\text { tissue) }\end{array}$ \\
\hline
\end{tabular}

The revised Atlanta classification of acute pancreatitis established in 2008 identifies two phases of the disease: early and late[4]. Severity is classified as mild, moderate, or severe (Table 2). 


\section{International Journal of Science and Research (IJSR) \\ ISSN (Online): 2319-7064}

Index Copernicus Value (2013): 6.14 | Impact Factor (2014): 5.611

Table 2: Revised Atlanta Classification [4].

\begin{tabular}{|c|c|}
\hline Disease severity & Symptoms \\
\hline Mild acute & No organ failure \\
\cline { 2 - 2 } pancreatitis & No local or systemic complications \\
\hline \multirow{3}{*}{$\begin{array}{c}\text { Moderately } \\
\text { severe acute } \\
\text { pancreatitis }\end{array}$} & $\begin{array}{c}\text { Organ failure that resolves within } 48 \mathrm{~h} \\
\text { (transient organ failure) }\end{array}$ \\
\cline { 2 - 2 } & $\begin{array}{c}\text { Local or systemic complications without } \\
\text { persistent organ failure }\end{array}$ \\
\cline { 2 - 2 } $\begin{array}{c}\text { Severe acute } \\
\text { pancreatitis }\end{array}$ & Persistent organ failure ( $>48 \mathrm{~h})$ \\
\cline { 2 - 2 } & Single organ failure \\
\hline
\end{tabular}

A variety of predictive systems have been developed to help clinicians in predicting prognosis. These include Ranson's criteria (Table 3), APACHE II (Acute Physiology and Chronic Health Evaluation), and the BISAP (Bedside Index for Severity in Acute Pancreatitis) score [5], [6], [7]. Of these, the BISAP score represents a simple way to identify patients at risk of severity and increased mortality. A BISAP score greater than 3 is associated with a 7 to 12 -fold increase in the risk of developing organ failure (Table 4) [7]. Hemoconcentration, indicated by an admission hematocrit of $\geq 47 \%$ and subsequent failure of the hematocrit to decrease by 24 hours are risk factors for the development of pancreatic necrosis [8]. Older age ( $\geq 55$ years) and a body mass index $(\mathrm{BMI}) \geq 30$ are also known risk factors for more severe forms of pancreatitis [10].

Table 3: Ranson's Criteria [5].

\begin{tabular}{|c|c|c|}
\hline Criterion & $\begin{array}{c}\text { Non-gallstone } \\
\text { pancreatitis } \\
(1974)\end{array}$ & $\begin{array}{c}\text { Gallstone } \\
\text { pancreatitis } \\
(1982)\end{array}$ \\
\hline \multicolumn{2}{|c|}{ On admission } \\
\hline Age (y) & $>55$ & $>70$ \\
\hline White blood cells (/mm $\left.{ }^{3}\right)$ & $>16,000$ & $>18,000$ \\
\hline Blood glucose (mg/dL) & $>200$ & $>220$ \\
\hline Serum lactate dehydrogenase (IU/L) & $>350$ & $>400$ \\
\hline $\begin{array}{c}\text { Serum aspartate aminotransferase } \\
\text { (IU/L) }\end{array}$ & $>250$ & $>250$ \\
\hline \multicolumn{2}{|c|}{ During initial 48 } \\
\hline Hematocrit decrease (\%) & $>10$ & $>10$ \\
\hline Blood urea nitrogen increase (mg/dL) & $>5$ & $>2$ \\
\hline Serum calcium (mg/dL) & $<8$ & $<8$ \\
\hline Arterial po 2 (mmHg) & $<60$ & NA \\
\hline Serum base deficit (mEq/L) & $>4$ & $>5$ \\
\hline Fluid sequestration (L) & $>6$ & $>4$ \\
\hline
\end{tabular}

Table 4: BISAP Scoring System [7].

\begin{tabular}{|c|}
\hline BUN $>25 \mathrm{mg} / \mathrm{dL}$ \\
\hline Impaired mental status (Glasgow Coma Scale $<15)$ \\
\hline SIRS: two or more of the following \\
\hline Temperature $<36^{\circ} \mathrm{C}$ or $>38^{\circ} \mathrm{C}$ \\
\hline Respiratory rate $>20$ breaths $/ \mathrm{min}$ or $\mathrm{P}_{\mathrm{a}} \mathrm{CO}_{2}<32 \mathrm{mmHg}$ \\
\hline Pulse $>90$ beats $/ \mathrm{min}$ \\
\hline White blood cells $<4000$ or $>12,000$ cells $/ \mathrm{mm}^{3}$ or $>10 \%$ \\
immature bands \\
\hline Age $>60$ years \\
\hline Pleural effusion \\
\hline
\end{tabular}

\section{Role of imaging in diagnosis}

The Atlanta classification in 1992 and its revision in 2008 provide a radiographic classification system for diagnosis and management of acute pancreatitis [3]. Contrast-enhanced multi-detector CT (CECT) is the primary imaging modality used for further evaluation when acute pancreatitis is suspected or diagnosed clinically. Its speed and reproducibility, as well as its ability to accurately demonstrate morphologic changes in acute pancreatitis, make it an ideal first step in imaging of patients with acute pancreatitis. When is the best time frame in which to perform CT after the patient's initial presentation? It is generally accepted that doing CT before 48 hours, may significantly underestimate disease severity on the basis of imaging characteristics [12], [13]. CT should be used in patients who are classified as having severe pancreatitis or are at risk of developing severe pancreatitis, ideally after 72 hours, to best assess the full extent of the disease [12]. In addition, ultrasound (US) is often performed early, regardless of the severity, to help establish an etiology for the pancreatitis (i.e. the presence of cholelithiasis or choledocholithiasis) and direct the need for further endoscopic or surgical management [endoscopic retrograde cholangiopancreatography (ERCP) or cholecystectomy] [13]. The revised Atlanta classification subdivides acute pancreatitis into two types: interstitial edematous pancreatitis (IEP) and necrotizing pancreatitis by the presence or absence of necrosis. Mortality of up to $23 \%$ and life-threatening complications, including secondary infection almost all occur in patients with necrosis [14]. Image description and classification are also determined by whether imaging is performed early ( $<4$ weeks from time of onset) or later ( $>4$ weeks; Table 5) [11], [12].

Table 5: Revised Atlanta Classification for Imaging [11], [12].

\begin{tabular}{|c|c|c|}
\hline Pancreatitis & Collection & Infection \\
\hline \multicolumn{3}{|c|}{$<4 w k$} \\
\hline IEP & APFC & \pm Infection \\
\hline \multirow[t]{4}{*}{ Necrotizing pancreatitis } & PNPFC & \\
\hline & Parenchymal necrosis & \pm Infection \\
\hline & Peripancreatic necrosis & \\
\hline & Mixed necrosis & \\
\hline \multicolumn{3}{|c|}{$>4 w k$} \\
\hline IEP & Pseudocyst & \pm Infection \\
\hline Necrotizing pancreatitis & WOPN & \pm Infection \\
\hline
\end{tabular}

APFC- acute peripancreatic fluid collection;

IEP- interstitial edematous pancreatitis;

PNPFC - post-necrotic pancreatic fluid collection; WOPN walled-off pancreatic necrosis.

In patients with acute IEP, CT typically reveals an enlarged pancreas. There may also be varying amounts of peripancreatic fluid. At $<4$ weeks, these fluid collections are termed acute peripancreatic fluid collections (APFCs) They are often the result of leakage of pancreatic enzymes from a ruptured side-branch duct. The majority of these collections are spontaneously resorbed within the first few weeks after onset of pancreatitis. 


\section{International Journal of Science and Research (IJSR) \\ ISSN (Online): 2319-7064 \\ Index Copernicus Value (2013): 6.14 | Impact Factor (2014): 5.611}

After 4 weeks, approximately $10-20 \%$ of patients with IEP and APFCs can develop pseudocysts as a complication of acute pancreatitis [12]. Pseudocysts are identified on CT by the presence of an identifiable, smooth, and uniform wall. Like APFCs, pseudocysts have purely fluid contents and may maintain a connection to the pancreatic ducts, resulting in amylase- and lipase-rich fluid. Secondary infection of pseudocysts is rare and is often manifest as gas bubbles within the pseudocyst on CT, although this is not always the case. If the patient displays signs and symptoms of infection, fine needle aspiration (FNA) of the cyst for Gram staining and culture may be required for a diagnosis. Even less common than pseudocyst infection is the occurrence of secondary infection in patients with IEP and APFCs. In a retrospective series to evaluate complications and fluid collections in patients with acute mild pancreatitis, Lenhart and Balthazar found no complications at all in patients without peripancreatic fluid collections (IEP without APFC) [15].

If evidence of necrosis is detected on CECT, then the patient is categorized as having necrotizing pancreatitis. This category is further subdivided according to the Atlanta classification based on the location of the necrosis, which in the first 4 weeks termed post-necrotic pancreatic fluid collection (PNPFC), also sometimes is referred to as acute necrotic collection (ANC). Acute necrotizing pancreatitis can involve (1) parenchymal necrosis alone (only $5 \%$ of cases), (2) peripancreatic necrosis alone, or (3) mixed parenchymal and peripancreatic necrosis.

Pancreatic parenchymal necrosis alone is relatively uncommon in comparison to the other two forms of necrotizing pancreatitis, accounting for only $5 \%$ of cases

Isolated peripancreatic necrosis in the absence of parenchymal necrosis is seen in up to $20 \%$ of cases. These patients typically have a better prognosis than patients with other types of necrotizing pancreatitis owing to preservation of the gland itself [11].

The most common form is mixed parenchymal and peripancreatic necrosis, which is seen in $75-80 \%$ of cases of acute necrotizing pancreatitis. PNPFCs can sometime be difficult to distinguish from APFCs, especially within the first week after diagnosis, and MRI (or occasionally US) can be useful to visualize the debris and complexity in necrotic collections [12].

After approximately 4 weeks, if the necrotic collections are no resorbed, the necrosis can mature and develop a thick wall, termed walled-off pancreatic necrosis (WOPN) Distinguishing WOPN from pseudocysts is important, as management strategies differ for these two types of collections. Both PNPFCs and WOPNs can become infected. This is suggested by the presence of gas within the necrotic collections or extraluminal gas bubbles, exluding perforation or fistular communication with the gastrointestinal tract. As with pseudocysts, if no gas is seen but there is other clinical evidence of infection, FNA for Gram staining and culture should be performed [11],[12].

Other CT grading systems have been developed over the last two decades. Most notable is the CT severity index proposed by Balthazar et al in 1990 [16]. This allows radiologists to grade the severity of pancreatitis on a 10-point scale, with points allotted for the amount of peripancreatic inflammation and fluid collections, as well as the amount of pancreatic necrosis $(<30 \%, 30-50 \%$, or $>50 \%)$. This was followed in 2004 by a modified CT severity index designed by Mortele et al that incorporates extrapancreatic complications in the scoring system and simplifies analysis of the degree of pancreatic necrosis ( $<30 \%$ or $>30 \%$ ) (Table 6) [17].

MRI of the pancreas and MR cholangiopancreatography (MRCP) has been increasingly used to evaluate patients with acute pancreatitis. MRI has some advantages over CT: it does not use ionizing radiation, MRI/MRCP is superior to CT for evaluation of choledocholithiasis and the pancreatic ductal system and it distinguishes necrotic collections (PNPFCs and WOPNs) from non-necrotic collections (APFCs and pseudocysts) [11],[12]. In patients older than 40 years for whom no cause of pancreatitis has been identified, MRI can be especially useful in searching for underlying occult neoplasms as a cause of pancreatitis. Disadvantages of MRI include its relatively high cost and its impracticality for critically ill patients who are unable to tolerate long imaging times or effectively hold their breath for many sequences [18].

Both CECT and MRI are useful in the detection of other extrapancreatic complications of acute pancreatitis, including venous thrombosis, gastric varices, pseudoaneurysm formation and rupture, hemorrhage, ascites, fistulization and rupture of the GI tract, and pleural effusion.

Table 6: CT Severity Index and Modified CT Severity Index [16],[17].

\begin{tabular}{|c|c|c|c|}
\hline \multicolumn{2}{|l|}{ CT severity index } & \multicolumn{2}{|c|}{ Modified CT severity index } \\
\hline Prognostic indicator & Points & Prognostic indicator & Points \\
\hline $\begin{array}{c}\text { Pancreatic } \\
\text { inflammation }\end{array}$ & & Pancreatic inflammation & \\
\hline Normal pancreas & 0 & Normal pancreas & 0 \\
\hline $\begin{array}{l}\text { Enlargement of } \\
\text { pancreas }\end{array}$ & 1 & $\begin{array}{c}\text { Pancreatic abnormalities } \\
\text { with or without } \\
\text { peripancreatic } \\
\text { inflammation }\end{array}$ & 2 \\
\hline $\begin{array}{c}\text { Pancreatic } \\
\text { abnormalities with } \\
\text { peripancreatic } \\
\text { inflammation }\end{array}$ & 2 & $\begin{array}{c}\text { Pancreatic or } \\
\text { peripancreatic fluid } \\
\text { collection or fat necrosis }\end{array}$ & 4 \\
\hline Single fluid collection & 3 & & \\
\hline $\begin{array}{c}\text { Two or more } \\
\text { collections or gas }\end{array}$ & 4 & & \\
\hline Pancreatic necrosis & & Pancreatic necrosis & \\
\hline None & 0 & None & 0 \\
\hline$<30 \%$ & 2 & $<30 \%$ & 2 \\
\hline $30-50 \%$ & 4 & $>30 \%$ & 4 \\
\hline \multirow[t]{2}{*}{$>50 \%$} & 6 & & \\
\hline & & $\begin{array}{c}\text { Extrapancreatic } \\
\text { complications (pleural } \\
\text { effusion, ascites, } \\
\text { parenchymal } \\
\text { complications, GI tract } \\
\text { involvement) }\end{array}$ & 2 \\
\hline
\end{tabular}

\section{Volume 5 Issue 3, March 2016}




\section{References}

[1] P.A. Banks, M.L. Freeman Practice guidelines in acute pancreatitis, Am J Gastroenterology, 101 (2006), pp. 2379-2400

[2] D. Gomez, A. Addison, A. De Rosa, A. Brooks, I.C. Cameron, Retrospective study of patients with acute pancreatitis: is serum amylase still required?, BMJ Open, 2 (2012)

[3] E.L. Bradley III, A clinically based classification system for acute pancreatitis, Atlanta, Ga, September 11 through 13, 1992, Arch Surg, 128 (1993), pp. 586590

[4] P.A. Banks, T.L. Bollen, C. Dervenis, H.G. Gooszen, C.D. Johnson, M.G. Sarr, et al., Classification of acute pancreatitis - 2012: revision of the Atlanta classification and definitions by international consensus, Gut, 62 (2013), pp. 102-111

[5] J.H. Ranson, K.M. Rifind, D.F. Roses, S.D. Fink, K. Eng, F.C. Spencer, Prognostic signs and the role of operative management in acute pancreatitis, Surg Gynecology Obstetric, 139 (1974), pp. 69-81

[6] W.A. Knaus, E.A. Draper, D.P. Wagner, J.E. Zimmerman, APACHE II: a severity of disease classification system,Crit Care Med, 13 (1985), pp. 818-829

[7] V.K. Singh, B.U. Wu, T.L. Bollen, K. Repas, R. Maurer, R.S. Johannes, et al., A prospective evaluation of the bedside index for severity in acute pancreatitis score in assessing mortality and intermediate markers of severity in acute pancreatitis, Am J Gastroenterology, 104 (2009), pp. 966-971

[8] J.D. Baillargeon, J. Orav, V. Ramagopal, S.M. Tenner, P.A. Banks, Hemoconcentration as an early risk factor for necrotizing pancreatitis, Am J Gastroenterology, 93 (1998), pp. 2130-2134

[9] J. Martinez, J. Sanchez-Paya, J.M. Palazon, J. SuazoBarahona, G. Robles-Diaz, M. Perez-Mateo, Is obesity a risk factor in acute pancreatitis? A meta-analysis, Pancreatology, 4 (2004), pp. 42-48

[10] O. Sadr-Azodi, N. Orsini, A. Andren-Sandberg, A. Wolk, Abdominal and total adiposity and the risk of acute pancreatitis: a population-based prospective cohort study,Am J Gastroenterol, 108 (2013), pp. 133139

[11]Acute Pancreatitis Classification Working Group, Revision of the Atlanta classification of acute pancreatitis, (Published April 2008) http://pancreasclub.com/wp-

content/uploads/2011/11/AtlantaClassification.pdf[Acce ssed November 15, 2012]

[12] R.F. Theoni, The revised Atlanta classification of acute pancreatitis: its importance for the radiologist and its effect on treatment, Radiology, 262 (2012), pp. 751-764

[13] American College of Radiology. ACR appropriateness criteria

(Published 2010) http://www.acr.org/ /media/ACR/Documents/Ap pCriteria/Diagnostic/AcutePancreatitis.pdf [Accessed November 15, 2012]
[14]E.J. Balthazar, Acute pancreatitis: assessment of severity with clinical and CT evaluation, Radiology, 223 (2002), pp. 603-613

[15]D.K. Lenhart, E.J. Balthazar, MDCT of acute mild (nonnecrotizing) pancreatitis: abdominal complications and fate of fluid collections, Am J Roentgenol, 190 (2008), pp. 643-649

[16] E.J. Balthazar, Acute pancreatitis: value of CT in establishing prognosis, Radiology, 174 (1990), pp. 331-336

[17] K.J. Mortele, W. Weisner, L. Intrier, S. Shankar, K.H. Zou, B.N. Kalantari, et al., A modified CT severity index for evaluating acute pancreatitis: improved correlation with patient outcome, Am J Roentgenol, 183 (2004), pp. 1261-1265

[18] F.H. Miller, A.L. Keppke, K. Dalal, J.N. Ly, V. Kamler, G.T. Sica, MRI of acute pancreatitis and its complications. Part 1, acute pancreatitis, Am J Roentgenol, 183 (2004), pp. 1637-1644

\section{Author Profile}

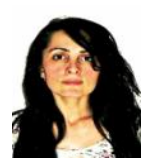

Alma Llukacaj received the Master degree in General Surgery in February 2008. Now, she is in the final process of getting the $\mathrm{PhD}$ in General Surgery. From June 2001, she works as attendant general surgeon at the Hospital University Center "Mother Theresa" in 